Esta revista forma parte del acervo de la Biblioteca Jurídica Virtual del Instituto de Investigaciones Jurídicas de la UNAM www.juridicas.unam.mx

www.bibliojuridica.org

PROBLEMA

Anuario de Filosofia

y Teoría del Derecho

\title{
EL INTERÉS SUPERIOR DEL NIÑO Y EL RAZONAMIENTO JURÍDICO
}

Ricardo GARRIDO ÁLVAREZ

Resumen:

El presente artículo reflexiona sobre el papel que desempeña el principio del "interés superior del niño", contenido en la Convención Internacional de Derechos del Niño, en el razonamiento jurídico justificatorio. Dos ideas fundamentales son defendidas en él. Por un lado, que un uso no trivial del principio de interés superior significa adjudicación de derechos preexistentes, lo que implica ubicarse en un contexto de aplicación, es decir, con uso de los criterios dogmáticos y precedenciales pertinentes. Por otro lado, que la aplicación del principio y su utilización como premisa de justificación, supone identificar el tipo de norma en que se contiene el derecho adjudicado, lo cual proyecta requerimientos específicos en la explicitación del argumento justificatorio.

Palabras clave:

Interés superior del niño, razonamiento judicial, argumentación jurídica, protección de menores-principios, Convención Internacional de los Derechos del Niño.

Abstract:

A discussion of the principle of the "child's best interest" in legal adjudication is the topic of this essay. My main claim is twofold: first, that a 


\section{RICARDO GARRIDO ÁLVAREZ}

non-trivial use of the principle implies adjudication of pre-existing rights, and secondly, that the application of the principle implies a duty of identification of the norm that contains the adjudicated right.

Keywords:

Child's Best Interest, Judicial Reasoning, Legal Argumentation, Child Protection Standards, Convention on the Rights of the Child. 


\section{EL INTERÉS SUPERIOR DEL NIÑO Y EL RAZONAMIENTO JURÍDICO}

SUMARIO: I. Introducción. II. Sobre la idea de interés superior. III. Consecuencias argumentales. IV. Los argumentos y los derechos del niño. V. Conclusión.

\section{INTRODUCCIÓN}

Antes de exponer las tesis básicas vertidas en este artículo, creo necesario aclarar aquellas expectativas científicas y prácticas que el mismo no satisface. En primer lugar, este artículo no defiende una forma peculiar de actividad argumentativa. Por el contrario se construye con algunas de las categorías de lo que podríamos llamar la lógica y el razonamiento estándar. Ello no implica que en este artículo se adopte lo que se ha dado en llamar la tesis estándar de la argumentación jurídica o teoría de la argumentación jurídica defendida por Robert Alexy y Neil MacCormick. Aunque dichos autores son una referencia obligada y se recoge gran parte de sus tesis, esta exposición se construye sobre categorias lógico argumentales más elementales y se permite matizar las ideas de dichos autores en algunos puntos significativos en relación con la idea de interés superior. En segundo lugar, este artículo toma como punto de partida la tesis defendida, desde hace varios años, por el profesor chileno Miguel Cillero quien ha sostenido que, en el contexto normativo y cultural generado por la Convención Internacional de los Derechos del Niño (CIDN), el interés superior del niño supone la más amplia satisfacción de los derechos contenidos en la Convención. ${ }^{1}$ En tercer y último lugar, es necesario puntualizar que este texto se ha

1 Cillero Bruñol, Miguel, "El Interés superior del niño en el marco de la convención internacional sobre los derechos del niño", Justicia y Derechos del Niño, Santiago de Chile, núm. 9, 2007, pp. 125-141. El profesor Cillero ha defendido esta idea como compatible con diversos grados o niveles de cumplimiento, independientemente del tipo de norma de que se trate. En el contexto de este artículo y por evidentes vinculaciones con la teoría de la argumentación, esta idea se emparenta con una optimización paretiana como la defendida por Robert Alexy a propósito de su "mandato de optimización". 


\section{RICARDO GARRIDO ÁLVAREZ}

construido con la discreta intención de servir de ayuda a lo que suele ser una perplejidad mayor para los jueces que deben resolver casos de infancia: ¿cuál es el papel preciso que la noción de interés superior del niño ocupa como razón justificatoria de las decisiones de los jueces? i.e., ¿qué significa el interés superior cuando se usa para justificar la decisión acerca de un niño, niña o adolescente?

\section{SOBRE LA IDEA DE INTERÉS SUPERIOR}

Como se sabe, la idea de interés superior del niño está aludida en términos bastante precisos en el artículo 3 de la CIDN: "1. En todas las medidas concernientes a los niños que tomen las instituciones públicas o privadas de bienestar social, los tribunales, las autoridades administrativas o los órganos legislativos, una consideración primordial a la que se atenderá será el interés superior del niño".

Así situada, esta cláusula o principio goza de una amplia aceptación en el campo del derecho internacional de los derechos humanos ${ }^{2} \mathrm{y}$ ha sido, de hecho, invocada por abun-

\footnotetext{
2 Este trabajo no es un ensayo analítico, y por tanto, no explora lo que "sea" el interés superior del niño sino su función y uso en un razonamiento práctico justificatorio. Si bien las cuestiones conceptuales son importantes por sus consecuencias para la argumentación y la adjudicación, acá no se establece una definición operativa uniforme y el interés superior aparece referido como norma, criterio normativo, principio o regla, y ello fundamentalmente por dos órdenes de consideraciones: En primer lugar, porque aun cuando interesan particularmente las funciones del interés superior como razón justificatoria, la noción aun conserva áreas o zonas de significado más allá de su papel como criterio o premisa de razonamiento jurídico. Por otro lado, una de las cuestiones centrales que este trabajo defiende es que el interés superior puede implicar o contener una regla, un principio u otro criterio normativo dependiendo de las particularidades del caso para el que sirve de premisa justificatoria. Esto hace que este trabajo sea compatible con teorías competitivas acerca de cuestiones analiticas importantes en relación con las normas e.g. si la diferencia entre reglas y principios es una cuestión de esencia (conceptual) o si es de grado i.e., de la forma en que se argumenta con uno y otro (nota del autor).
} 
dante jurisprudencia Internacional ${ }^{3}$ y comparada al punto que la propia Corte Interamericana la convirtió en el eje de su ya célebre opinión consultiva OC17 sobre la condición jurídica del niño. Sin embargo, y no obstante las abundantes referencias normativas a la cláusula, muy poco se ha avanzado en la precisión de su contenido. Si bien la mayor parte de los textos legales y jurisprudenciales que usan la expresión parecen atribuirle un contenido normativo i.e, parece sugerir que se trata de una regla o principio para decidir, es poco lo que se ha adelantado en deslindar el alcance de esa norma, esto es, qué casos quedarían alcanzados por la misma y cuáles serían los contenidos (valores) a partir de los cuales se delimita el uso de ese estándar. En el contexto de la doctrina latinoamericana el profesor Miguel Cillero ha avanzado en esa dirección sugiriendo que, como la cláusula del Interés Superior está situada en un tratado de derechos humanos de los niños y éstos constituyen prescripciones valorativas específicas que se les atribuye atendida su dignidad, no cabe sino atribuirle el contenido de los propios derechos aludidos en la Convención. En términos simples el interés superior del niño consistiría en la

3 Corte Interamericana de Derechos Humanos, sentencia del 31 de enero de 2001, Serie C, No. 71, párrafo 89. Debe tenerse presente que en el contexto interamericano la Corte Interamericana de Derechos Humanos ha establecido el control de convencionalidad entendido como: "La Corte es consciente que los jueces y tribunales internos están sujetos al imperio de la ley y, por ello, están obligados a aplicar las disposiciones vigentes en el ordenamiento jurídico. Pero cuando un Estado ha ratificado un tratado internacional como la Convención Americana, sus jueces, como parte del aparato del Estado, también están sometidos a ella, lo que les obliga a velar porque los efectos de las disposiciones de la Convención no se vean mermadas por la aplicación de leyes contrarias a su objeto y fin, y que desde un inicio carecen de efectos jurídicos. En otras palabras, el Poder Judicial debe ejercer una especie de "control de convencionalidad" entre las normas jurídicas internas que aplican en los casos concretos y la Convención Americana sobre Derechos Humanos. En esta tarea, el Poder Judicial debe tener en cuenta no solamente el tratado, sino también la interpretación que del mismo ha hecho la Corte Interamericana, intérprete última de la Convención Americana”. 
más amplia satisfacción de los derechos a los que la convención se refiere en el resto del tratado.

No voy a problematizar esta aproximación sino que la asumo como correcta para el propósito de este trabajo. Sin embargo, hay varias consecuencias importantes, con incidencia argumental, que se desprenden de esta definición.

\section{Consecuencias ARGUmentales}

\section{Consecuencias relativas al contenido} de la cláusula (premisa)

En primer lugar, esta aproximación conceptual proyecta un núcleo o centro básico de significado para la cláusula: las decisiones estatales sobre el niño (sobre su persona) deben ser decisiones sobre, y acerca de sus derechos. Para el caso de los jueces y los funcionarios estatales (la convención impone obligaciones sobre entes no estatales también como la familia y la sociedad) lo anterior importa que las decisiones deben ser adjudicativas de derechos preexistentes de los niños. ${ }^{4}$ Una forma algo simplista de leer la obra de Cillero en este punto, es decir, ahí donde la Convención o cualquier otra norma de derecho internacional o nacional dice que debe atenderse el interés superior del niño, debe leerse que ello implica que debe resolverse y decidirse sobre cual sea su derecho en el contexto concreto de decisión del órgano estatal. En otras palabras, la legitimidad del Estado para intervenir en la vida de ese particular sujeto de derecho (persona) al que llamamos niño, es función de que la decisión institucional determine el alcance normativo de un derecho humano en un caso concreto. Por contraste, lo anterior trae como consecuencia que cualquier otro criterio de

4 La noción de preexistencia es importante de una teoría de la adjudicación y la argumentación jurídica y alude a la circunstancia de que el derecho funciona como un repertorio de razones preexistentes para la justificación de decisiones. En ese sentido una de las suposiciones ideológicas en las que este trabajo descansa es que el Derecho preexiste a las decisiones adoptadas conforme a él. 
decisión (la necesidad del niño, la justicia del caso, la idoneidad de la medida, etcétera) es políticamente ilegítimo y jurídicamente incorrecto.

De suyo este es uno de los grandes avances que se le atribuyen al consenso ético expresado en la amplia aceptación de la CIDN: el haber logrado la instalación de un nuevo paradigma en materia de políticas públicas y de decisión de asuntos de la infancia, que se traslada desde la doctrina de la situación irregular a una función adjudicativa y de distribución, protección y promoción de derechos. Más bien me atrevo a sugerir que esto ha implicado la consolidación de un mismo paradigma que es indiscutido para el caso de los adultos: la legitimidad de la actuación estatal queda marcada por el catálogo de derechos definidos en las constituciones de los estados democráticos de derecho.

En segundo lugar, lo anterior implica que la cláusula del interés superior tiene un contenido polisémico, pero no vago ni impreciso en términos de su aplicación. Es decir, puesto que decidir en consideración al interés superior del niño supone la aplicación y adjudicación de derechos preexistentes de los niños, el contenido cambia en función de la calificación jurídica del caso, i.e., la que define la situación material como alcanzada por una norma en particular (un caso) lo que en el contexto de la teoría de la argumentación, se define como un problema de relevancia, ${ }^{5}$ pero no es ne-

5 MacCormick, Neil, "La argumentación silogística: una defensa matizada", Doxa, Cuadernos de Filosofía del Derecho, 30, España, 2009, pp. 321-334. Siguiendo una teoría de Corte Hartiano, MacCormick ha defendido la idea de que en términos argumentativos y de adjudicación es posible identificar casos dificiles y fáciles dependiendo de si se presentan, o no, ciertas dificultades en su aplicación que se traducen en problemas para establecer la premisa justificatoria. Así, efectúa una división cuatripartita de casos dificiles, según se trate de problemas: a) de interpretación; b) de relevancia; c) de prueba o d) de calificación. Los dos primeros afectan a la premisa normativa y los dos últimos a la premisa fáctica. En cuanto al problema de relevancia se relaciona con la existencia de un criterio normativo para el caso, sin embargo el juez no tiene claro como aplicarla. 
cesariamente vago como estándar de decisión. Lo anterior es altamente significativo en el ámbito de la actividad argumental y particularmente en el contexto de la justificación racional de decisiones práctico jurídicas, ${ }^{6}$ puesto que ello implicará la utilización de las categorias dogmáticas al uso respecto del derecho que se identifica como vulnerado o cuya aplicación o consecuencias jurídicas deben ser establecidas. Existen poderosas razones en apoyo a la idea de que en las "fundamentaciones jurídicas la dogmática desempeña un papel central en la determinación de las normas jurídicas aplicables como premisa argumentativa vinculado a las pretensiones de validez del derecho en general". ${ }^{7}$ Lo anterior suele identificarse en la teoria de la argumentación como la función de descarga de la dogmática jurídica en el sentido de que "se puede adoptar en las fundamentaciones dogmáticas enunciados ya comprobados y aceptados al menos de manera provisional lo que supone una descarga en la medida en que, sin una razón especial, no es necesaria una nueva comprobación. Se puede renunciar a discutir de nuevo en cada caso cada cuestión de valoración. Esta función de descarga no es sólo indispensable para el trabajo de los tribunales, que tiene lugar bajo la presión del tiempo; también es importante para la discu-

6 Bix, Brian, Diccionario de teoría jurídica, trad. de Enrique Rodríguez Trujano y Pedro A. Villarreal Lizárraga, México, UNAM, Instituto de Investigaciones Juridicas, 2009, p. 220. La idea de racionalidad que se defiende en el texto no es de ninguna manera exhaustiva, alude a "cierta comprensión al evaluar las decisiones, tanto de los medios para un fin, como los objetivos últimos". Asimismo no he juzgado necesario diferenciar las nociones de racionalidad y razonabilidad aunque en ciertos contextos relevantes para la argumentación, ello pueda ser de la mayor trascendencia.

7 Alexy, Robert, Teoría de la argumentación jurídica, 2a. ed., trad. de Manuel Atienza e Isabel Espejo, Madrid, Centro de Estudios Políticos y Constitucionales, 2008, pp. 255-257. Entendiendo a la dogmática jurídica como una serie de enunciados que se refieren a las normas establecidas y a la aplicación del derecho, relacionados entre sí coherentemente, discutidos en el marco de una ciencia jurídica que funciona institucionalmente y que tienen contenido normativo. 
sión científica jurídica. También aquí -como en todos ladoses imposible volver a discutirlo todo". 8

Esta descarga de "no volver a discutirlo todo", es sumamente importante en materia de interés superior del niño. Existe la creencia (no sólo entre los operadores jurídicos si no que también en cierta doctrina) de que el interés superior del niño en un contexto de decisión particular (e.g. un caso judicial) abre la posibilidad de discutir en cada caso concreto cual sea este interés en función de los contextos y circunstancias particulares del niño, y esto es insostenible. No puede afirmarse que los jueces de un estado democrático de derecho estén obligados a adjudicar derechos preexistentes usando como base de su argumentación criterios de validez intersubjetiva: ${ }^{9}$ la ley, el precedente, la dogmática, salvo cuando el destinatario de la decisión es un niño, en cuyo caso el criterio valorativo usado para decidir siempre podría ser revisado y discutido en función de la particular definición de lo que sea su interés en ese caso. Esto anula por completo la idea de que los niños son sujetos de derecho al igual que los adultos y conspira contra la naturaleza de la función jurisdiccional en un estado de derecho que parece, a luz de los derechos de los niños, totalmente desprovista de legitimidad política (es un acto de autoridad en sentido neto).

Por el contrario, la tesis del interés superior como sinónima de derechos del mismo, sólo puede construirse en el

8 Idem. El autor en su obra distingue seis funciones a valorar positivamente en la dogmática jurídica 1) estabilización 2) de progreso 3) de descarga 4) técnica 5) de control 6) heurística.

9 Ibidem, pp. 213-222. En los argumentos jurídicos pueden distinguirse dos aspectos de justificación: La justificación interna, cuyo objeto es establecer si la decisión tomada se sigue lógicamente de las premisas que se aducen como fundamentación, y la justificación externa, cuyo objetivo es la corrección de las premisas usadas en la justificación interna, es en esta fase en donde se identifican reglas o formas de justificación externa entre las que se encuentran la ley, la dogmática y el precedente. Con esta forma de argumentación lo que se pretende es asegurar que los jueces aplican las normas que como sociedad nos hemos dado. 
contexto de la naturaleza institucional de los jueces de un estado democrático de derecho, que entiende que las decisiones de éstos son actos de aplicación de reglas y criterios preexistentes y que por lo tanto, la justificación racional de sus decisiones se da en un contexto de aplicación y no en un contexto de justificación o fundamentación del criterio normativo usado.

Esto es válido incluso para quienes han sostenido tesis contextuales acerca de la significación de la cláusula del interés superior del niño. Aún en esos casos, y en periodos anteriores a la vigencia de la CIDN, los esfuerzos se han centrado en establecer algunos criterios que permitan discernir qué implica el interés superior del niño en contextos generales, pero acotados e.g. casos de custodia parental, de manera de aislar algunos criterios permanentes que sean consecuentes con la idea de interés diferenciado de los niños respecto de sus padres. ${ }^{10}$

Concebir las decisiones estatales como adjudicativas de derechos preexistentes de los niños proyecta un desafio de enorme trascendencia y dificultad para los operadores jurídicos en orden a identificar el criterio preexistente, determinar su alcance para el caso (interpretarlo) y aplicarlo en consonancia con el Derecho Internacional de los Derechos Humanos. Pero todo ello no implica que esta sea una actividad abierta a la discusión, caso por caso, de la idoneidad y pertinencia del criterio usado para resolver.

10 Goldstein, Joseph et al., ¿En el interés superior de quién es? Beyond the Best Interests of the Child. Derecho, infancia $y$ familia, compilado por Mary Beloff, Barcelona, Biblioteca Yale de Estudios Jurídicos, 2000, pp. 115-129. En el caso de determinar la ubicación y el proceso de ubicación de los niños cuya custodia es objeto de acción legal, los autores aíslan las siguientes directrices para dar contenido al interés superior del niño: 1) Las decisiones de ubicación deberían salvaguardar la necesidad de continuidad en las relaciones personales, 2) Deberían reflejar el sentido temporal del niño y no el de los adultos, 3) Deben tener en cuenta la incapacidad de la ley en supervisar las relaciones interpersonales y los límites del conocimiento para realizar predicciones a largo plazo. 


\section{Consecuencias relacionadas con la adjudicación}

En tercer lugar, y como se adelantaba, la extensión de la fórmula que sostiene que el interés Superior del Niño es la más amplia satisfacción de sus derechos, diría en su versión adjudicativa, que el compromiso del interés superior del niño tiene como finalidad la aplicación y adjudicación de un derecho preexistente a la decisión del juez que aplica el contenido de ese derecho. Esto trae como corolario algo elemental pero de la mayor trascendencia práctica e institucional: Los jueces de un estado democrático de derecho deben justificar su decisión explicitando la premisa justificatoria utilizada, esto es, el criterio normativo y valorativo que han resuelto emplear. Así, se contará con la evidencia de estar adjudicando un derecho preexistente. Si este criterio no se explicita y si no se expone la cadena de argumentos que llevan de la premisa a la decisión final entonces no podemos distinguir la actividad jurisdiccional de un acto político neto.

A estas alturas podrian replicarse dos cosas: La primera de ellas es que todo lo señalado es algo de la mayor obviedad: los jueces de un estado moderno (esto remite a las expectativas modernas sobre la racionalidad del estado y sus decisiones) siempre deben justificar las decisiones que adoptan e incluso comúnmente tienen la obligación legal y constitucional de hacerlo y la segunda, es que lo planteado no nos dice nada acerca de la forma especifica que debe revestir dicha justificación para el caso de los niños.

La primera observación (de que los jueces siempre deben justificar racionalmente sus decisiones) es certera, ${ }^{11}$ pero recordarlo en el caso de los derechos del niño no es trivial

11 Este artículo se construye sobre una concepción específica acerca de la función institucional propia de los órganos judiciales: resolver casos de conformidad a la ley, en la medida en que el juez use la ley para decidir podrá verse reflejado en el argumento el criterio normativo que usa como premisa justificatoria. Esto, por supuesto, proyecta concepciones también específicas para otros valores tradicionalmente adscritos a la función judicial: la seguridad jurídica que es vista como seguridad del criterio 


\section{RICARDO GARRIDO ÁLVAREZ}

por dos razones: La primera de ellas es que la cláusula del interés superior no es un añadido ni excepción a los criterios normativos pertinentes a la resolución del caso en que el niño está involucrado, sino al contrario, el interés superior del niño expresa el contenido de la premisa normativa del argumento justificatorio. La segunda es que la justificación moderna para la exigencia de racionalidad en los actos judiciales se hace más acuciante en los casos de los niños, justamente porque éstos raramente son puestos como sujetos de autogobierno y deliberación por el sistema institucional y particularmente el judicial e.g., el sistema procesal. La segunda objeción intento abordarla en la segunda parte de este artículo, pero desde luego, puede sugerirse que el caso de los niños impone una regla o principio de maximización en el disfrute de sus derechos.

Para una mejor explicación de lo que se viene sosteniendo puede ser útil recordar un caso que suele ser tenido como paradigmático en el contexto de nuestra tradición cultural judeo-cristiana en el ámbito de las decisiones acerca de los niños, el caso del rey Salomón.

Por entonces dos mujeres prostitutas fueron a presentarse al rey. Se pararon ante él, y dijo una de ellas: "Por favor, mi señor, esa mujer y yo vivíamos en una misma casa, y di a luz, mientras ella estaba conmigo. A los tres días de mi parto, parió también la mujer esa; estábamos juntas, no había nadie más en la casa, sólo nosotras dos. Una noche murió el hijo de la mujer esa, porque ella había permanecido acostada sobre él. Se levantó durante la noche y, mientras tu servidora dormía, tomó a mi hijo de mi costado y lo acostó en su regazo, y a su hijo, el que estaba muerto, lo acostó en el mío. Al amanecer me levanté para amamantar a mi hijo, y

general que la ley expresa, la paz social que se consigue como resultado de la sujeción a criterio compartidos y aceptados por los miembros de la comunidad e incluso para la justicia, puesto que en una democracia liberal pluralista en lo valorativo, lo que sea "lo suyo, de cada cual" es definido en asambleas deliberativas en las que las distintas concepciones acerca de lo que es justo pueden verse enfrentadas (nota del autor). 


\section{EL INTERÉS SUPERIOR DEL NIÑO Y EL RAZONAMIENTO JURÍDICO}

¡estaba muerto! Pero lo examiné bien a la luz de la mañana y vi que no era mi hijo, el que yo había parido". La otra mujer repuso "No, por cierto, mi hijo es el vivo y tu hijo es el muerto". Pero la otra replicaba: "No, al contrario, tu hijo es el muerto y mi hijo es el vivo". Y seguían discutiendo ante el rey. Dijo el rey: "Esa dice: Este es mi hijo, el vivo, y tu hijo es el muerto, y la otra dice: no, al contrario, tu hijo es el muerto, y mi hijo es el vivo". Entonces ordenó el rey: "Traedme una espada". Presentaron la espada al rey éste sentenció: "Cortad al niño vivo en dos partes y dad mitad a una y mitad a otra". A la mujer de quien era el niño vivo se le conmovieron las entrañas por su hijo y replicó al rey: "Por favor, mi señor, que le den a ella el niño vivo, pero matarlo, No, ¡no lo matéis!", mientras la otra decía: "Ni para mí, ni para ti: ¡Que lo corten!». Sentenció entonces el rey: «Entregadle a ella el niño vivo, ¡no lo matéis! ella es su madre». El juicio pronunciado por el rey llegó a oídos de todo Israel y cobraron respeto al rey, al ver que dentro de él habia una sabiduría divina con la que hacer justicia. ${ }^{12}$

Existe una multitud de aspectos interesantes en este caso, pero sólo voy a comentar aquellos con incidencia argumental. Una de las muchas razones que hacen de este ejemplo un caso inviable desde el punto de vista institucional, es que nadie asume que quien debe decidir la situación futura de un niño en un Estado de derecho moderno sea particularmente sabio (depositario de la sabiduría de Dios), no descarto que este pueda ser el caso de algunos jueces, pero desde luego, su sabiduría no es la razón por la que desempeñan la función institucional de juez. Por las razones postmetafísicas (asociadas a la ausencia de Dios como criterio de validez intersubjetiva de los fenómenos) que configuran las suposiciones ideológicas de nuestro diseño institucional, tendemos a atribuir a los jueces la misma calidad moral que a los demás (es un ciudadano más de la comunidad política de la que todos somos miembros) por lo que, de

12 Libro de los reyes, capítulo II 3.16, Biblia de Jerusalén, Jerusalén, conocido como el juicio de Salomón. 
partida, no le asigno la función de proveer criterios normativos acerca de lo que es correcto o justo para el caso, ${ }^{13}$ puesto que ello supondría que se encuentra habilitado para imponerme sus reglas en cualquier caso en que deba decidir sobre asuntos que me conciernen a mí. En vez de eso, nuestros arreglos institucionales tienden a asumir que todas las personas somos los mejores jueces de lo que nos conviene (lo que se asegura a través de un amplio rango de garantías constitucionales) y para aquellos casos en que, inevitablemente, debemos formular reglas sociales de convivencia mutua, se diseñan mecanismos de deliberación política (típicamente asambleas deliberativas) que hagan probable que la resultante del debate pueda ser aceptada por los miembros de la comunidad politica como un criterio racionalmente justificado (Habermas). Es absolutamente posible (no autocontradictorio) que lo adoptado por esas asambleas esté racionalmente justificado y por lo tanto sea válido en una comunidad de hombres libres y racionales que se autogobiernan si puedo mostrar (contrafácticamente) que cualquier persona racional aceptaría las consecuencias que se siguen de su aceptación general (Principio U).

De esta suerte, la teoría de la argumentación distingue dos niveles o grados para la racionalidad de los criterios valorativos o normas. ${ }^{14}$

En un primer nivel de fundamentación o justificación de las reglas o criterios valorativos, se trata de encontrar un criterio que satisfaga estándares de idoneidad y razonabilidad del mismo, dadas ciertas condiciones generales. En este caso, el rol del debate público e informado acerca de la norma, que debe darse en la etapa de creación de las leyes por ejemplo es servir de foro que haga probable que las re-

13 Atria, Lemaitre Fernando, "Seguridad jurídica y derechos fundamentales: sobre predecibilidad y autogobierno", en Bordali, Andrés (comp.), Justicia constitucional y derechos fundamentales, 2a. ed., Santiago, Lexis Nexis, 2007, pp. 7-16.

14 Günther, Klaus, "Critical Remarks on Robert Alexy Special Case Thesis”, Ratio Iuris, vol. 6, núm. 2, pp. 143-156. 
glas satisfagan las pretensiones de justificación (de validez), es decir, que puedan aceptarlas luego de examinarlas porque las consideran pertinentes dadas ciertas condiciones generales. En un segundo nivel, de aplicación, se trata de evaluar y establecer que el caso que debe ser resuelto por los jueces está alcanzado por la regla general que ya ha sido justificada o fundamentada. No se supone que las reglas puedan ser evaluadas nuevamente en su pertinencia porque ello supondria que los jueces tienen una función deliberativa que el sistema institucional suele negarles. Más se trata de que determinen que su caso está verdaderamente alcanzado por la norma y establezcan las consecuencias que se siguen de esa circunstancia. En este sentido, la actividad argumentativa está contextualizada por un criterio valorativo democráticamente adoptado $\mathrm{y}$, consiguientemente, justificado o fundamentado.

Así las cosas, resulta que hay por lo menos, dos razones por las que el caso del rey Salomón resulta anómalo desde el punto de vista de la teoría de la argumentación. En primer lugar porque, por consideraciones post metafísicas, Salomón está legitimado para imponer sus reglas, es decir, los criterios que él considera como justos o apropiados para el caso, en tanto nuestros jueces nunca están política ni jurídicamente habilitados para hacer eso, sino que deben aplicar nuestras reglas. El conjunto de garantías procesales y constitucionales aplicables a la actividad jurisdiccional puede ser visto como un complejo de mecanismos para asegurarnos que el juez haga precisamente eso, aplique la ley y sólo la ley como criterio decisorio del caso. La segunda anomalía argumental está referida a la premisa fáctica (inexistente en verdad) del argumento solomoniano. En efecto, Salomón no recibe la causa a prueba; su sabiduría hace innecesaria tal cosa. Hoy por hoy el igual valor de los involucrados en el proceso de decisiones de autoridad (en el proceso: las partes y el juez) exige que el juez establezca la existencia de los hechos conforme a criterios de validez intersubjetiva, puesto que la racionalidad funciona como el 
único criterio de objetividad en una comunidad de hombres libres y moralmente iguales.

De todo lo anterior resulta que, cuando son los niños los destinatarios de la decisión judicial, no existen razones teórico generales que justifiquen que el juez resuelva el caso evaluando él mismo cual es el interés superior del niño, como si fuera una cosa distinta de los derechos preexistentes en reglas ya justificadas o fundamentadas i.e., como un criterio que pueda derrotar a las reglas aplicables a la solución del caso sometido a consideración del juez. Ello supondría que en el caso de los niños y niñas el juez sí aplica sus reglas y no nuestras reglas y por lo tanto que no reconocemos a los niños su participación como miembros activos de la comunidad política. Desde la CIDN ello es insostenible. Esto dota a la tesis de Cillero de un respaldo científico con base en la teoría de la argumentación. La otra consecuencia es que si el juez debe aplicar nuestras reglas y los niños son verdaderamente miembros de la comunidad política i.e., les distribuimos esa cualificación, 15 ello implica que los asuntos sobre los que se resuelve les conciernen a ellos y no al decidor, por lo que su propia voz acerca de lo que es pertinente para el caso, debe ser un insumo, cuando no una premisa dentro del repertorio de razones que justifican la decisión del juez del caso.

\section{Consecuencias argumentales vinculadas} con el carácter de derecho fundamental del interés superior del niño

En cuarto lugar, es necesario destacar que atribuir a la cláusula del interés superior del niño una significación normativa (derecho garantía dice Cillero) tiene un incidencia gravitante en la estructura del razonamiento que invoca la cláusula como razón decisoria. En efecto, se ha sostenido

15 Ferrajoli, Luigi, Democracia y garantismo, 2a. ed., edición de Miguel Carbonell, Madrid, Trotta, 2010, p. 373. 
que el valor normativo de la cláusula deviene de su posición dentro de un tratado de derechos humanos por lo que hay argumentos sistemáticos y funcionales ${ }^{16}$ que respaldan la idea que ello significa argumentar con derechos fundamentales. Lo relevante de este posicionamiento normativo específico, es que los derechos constitucionales fundamentales o humanos funcionan en una sola dirección argumental. La que promueve su regulación sobre un mínimo de sentido interpretativo del contenido del derecho. Para decirlo metafóricamente funcionan sólo hacia adelante puesto que permiten bloquear ciertas interpretaciones como implausibles para el contenido elemental del derecho y favorecen "hacia adelante", aquellas que fortalecen los valores expresados en el contenido mínimo o básico del derecho. Soy consciente de que esta es una cuestión más interpretativa que argumental (aunque la interpretación de los criterios normativos juegue un rol importante en el contexto, y dentro de, una teoría de la argumentación), pero es evidente que esta característica determina la estructura general del argumento justificatorio en materia de derechos humanos, puesto que los derechos excluyen ciertas justificaciones para la acción o la inacción. "La metáfora del equilibrio puede inducir a error tanto como la vaga idea de que los derechos son absolutos. Si todas las afirmaciones en conflicto deben ponderarse unas con otras, entonces las afirmaciones de los derechos no son esencialmente diferentes a las de interés. Pero eso es una simplificación, porque cuando hay derechos en juego, el gobierno no puede justificar no exigirlos afirmando que del otro lado existen algunos intereses discernibles". De esta suerte, la toma de decisiones no es una mera cuestión de equilibrios y también tiene un "sesgo absoluto". ${ }^{17}$ Ello

16 Wroblewski, Jerzy, Constitución y teoría general de la interpretación jurídica, trad. de Arantxa Azurza, Madrid, Civitas, 1985, passim.

17 Holmes, Stephen y Sustein, Cass R., El costo de los derechos, trad. de Stella Mastrangelo, Buenos Aires, Siglo Veintiuno Editores, 2011, pp. 121-133. Cuando se trata de derechos algunos argumentos no solo no tienen peso suficiente, sino que son por completo inadmisibles, esto vale 
justifica el tratamiento y la inclusión de la cláusula en la CIDN puesto que de un lado estarian los intereses discernibles en un caso y por otro el interés superior del niño con base en su dignidad. El propio adalid de la ponderación argumentativa ha dicho por un lado que su teoría de los derechos promueve una concepción maximizadora como óptimo paretiano y que cuando es la dignidad la que se discute esta se comporta en verdad como una regla puesto que la dignidad no admite limitaciones o restricciones. ${ }^{18}$

En quinto y último lugar en esta sección, cabe preguntarse lo siguiente: Si el Interés Superior del Niño consiste en la más amplia satisfacción de los derechos contenidos en la Convención de los Derechos del Niño, ¿por qué era necesario ponerlo de ese modo?, es decir, ¿Por qué era necesario el uso de la cláusula del interés superior del niño?, ¿No bastaba con los derechos del tratado? Después de todo y desde el punto de vista adjudicativo lo que se aplica a la resolución del caso son los derechos y su significado normativo (dogmático y precedencial). No puedo abordar acá todas las razones por las que esto es así, lo que incluye una gran cantidad de consideraciones históricas sociales por cierto, pero si puedo decir algunas cosas importantes para la argumentación en derechos del niño.

De un lado, es necesario advertir que la redacción del artículo 3 de la CIDN es bastante indicativa de la necesidad de una inclusión del criterio como razón decisoria diferenciada. Ese artículo habla de "todas las medidas concernientes a los niños", ello pone en evidencia algo que se ha visto entorpecido por los mecanismos procesales usados en nuestros sistemas institucionales. La circunstancia de que

tanto para el derecho privado como para la constitución, en este sentido los sistemas de derecho (particularmente el norteamericano) son absolutistas, excluyen de manera incondicional algunas razones y solo proscribe condicionalmente ciertas acciones e inacciones.

18 Universidad de Alicante, Departamento de filosofía del derecho, "Entrevista a Robert Alexy", Doxa Cuadernos de Filosofía del Derecho, trad. de Manuel Atienza, España, núm. 24, Universidad de Alicante, pp. $17-21$. 
muchas veces los asuntos que conciernen a los niños y que como consecuencia deben consistir en adjudicar sus derechos son presentados como los asuntos de terceros. El típico (en sentido lógico de tipo) caso de las disputas parentales que son presentados como un conflicto y una cuestión concerniente a los derechos de los padres son el mejor o peor ejemplo de la invisibilidad de los evidentes y trascedentes derechos de los niños implicados en una decisión como esa. No es exagerado sostener que toda la teorización comparada relativa a la noción del Interés Superior anterior a la CIDN tenía como uno de sus propósitos fundamentales indicar que los niños eran destinatarios de esa decisión tanto como sus padres y que los criterios conforme a los cuales esa decisión debía abordarse requería un viraje en la perspectiva del decidor desde enfoques no (o menos) "adultistas". 19 Ese sólo merito justifica su inclusión y su permanencia en una dogmática de los derechos del niño.

Puede conjeturase que la correcta visualización y consiguiente ponderación argumentativa del juez respecto de los intereses de los niños en asuntos presentados por terceros al sistema judicial se haya visto dificultada por la concepción decimonónica predominante que entiende a la función jurisdiccional como de resolución de conflictos antes que adjudicativa de derechos preexistentes. De lo anterior se sigue una concepción estática del sistema jurídico, antes que una concepción dinámica o interna en la que el Derecho es usado por los miembros de la comunidad como un repertorio de razones preexistentes para la acción. No obstante el evidente interés teórico de la conjetura, no puedo desarrollar acá todas las consecuencias de la misma.

De otro lado, y en conexión íntima con lo anterior, los desarrollos teóricos vinculados a la noción de interés en relación con los derechos, se han centrado en la idea de que algunos intereses adquieren la forma de derechos por consideraciones relativas a la importancia valorativa especí-

19 Goldstein, Joseph et al., Beyond the best interests of the Child, 1973-1979, passim. 
fica del interés o a la relevancia social en la defensa de ciertos intereses por ejemplo, la libertad de expresión individual es importante y es un derecho por su papel en el campo de la convivencia democrática. En esa línea Joseph Raz, por ejemplo, ha indicado que la razón por la que algunos intereses son derechos y otros no, se vincula con el papel que los mismos (los derechos) desempeñan en el razonamiento práctico. "Afirmar que una persona tiene un derecho equivale a decir que un interés suyo constituye base suficiente para sujetar a otro a un deber (...) y tal afirmación también es relativa a las razones por las cuales (ese derecho) debe ser tomado con seriedad". 20 "Los juristas a menudo conciben que el derecho está compuesto por un conjunto de normas integradas vinculadas de justificación". ${ }^{21}$ Esta noción es básica para la idea de Interés superior del niño puesto que la idea está integrada por cadenas de reglas cuya inclusión en un razonamiento justificatorio se funda en la importancia valorativa de los derechos que integran la cláusula y adquieren la categoría de derechos excluyentes de otros intereses concurrentes merced a ese valor (en el contexto de la dogmática del derecho internacional se suele llamar a esta capacidad exclusionaria de la reglas que establecen derechos del niño, principio de protección especial).

\section{LOS ARGUMENTOS Y LOS DERECHOS DEL NIÑO}

Llegados a este punto y, asumiendo la idea básica de que el interés superior del niño impone un mandato adjudicativo específico, el de que las decisiones estatales (judiciales) acerca de los asuntos que conciernen a los niños son adjudicativos de sus derechos preexistentes queda por despejar la forma en que podemos asegurarnos de que ello ocurre. La cuestión es simple y, ciertamente, habitual: Cuando un

20 Raz, Joseph, La ética en el ámbito público, trad. de María Luz Melón, Barcelona, Gedisa, 2001, p. 282.

21 Ibidem, p. 283. 
juez invoca el interés superior del niño como motivo decisional, ¿cómo saber que el juez adjudica un derecho o bien está dando al estándar un contenido normativo (un derecho) y no lo está invocando, retóricamente, para avanzar su propia idea acerca de lo que es justo o apropiado para el caso? Y la respuesta es tan simple como la pregunta. E1 juez debe explicitar las reglas y/o principios que contienen los derechos que está aplicando o adjudicando de suerte que éstas son premisas de un argumento justificatorio, en que la decisión finalmente adoptada aparece como la conclusión lógica de las premisas usadas. La respuesta parece trivial (de hecho lo es) pero no lo es tanto por dos razones: en primer lugar porque, como se anticipaba supra, suele creerse que el interés superior del niño contiene un criterio valorativo adicional a las demás normas pertinentes a la resolución del caso que concierne al niño. La sugerencia de lo que va escrito es que es justamente lo contrario: la idea de interés superior remite a la adjudicación de los derechos pertinentes a la solución del caso, nada más y nada menos. Por razones asociadas a las dificultades interpretativas implicadas y los problemas propios del encuadre de los hechos en una hipótesis normativa compleja suele creerse que la operación argumental subsecuente es dificil en el caso de los niños, pero ello no es necesariamente así. Nada excluye que la adjudicación de un derecho quepa dentro de lo que la teoría jurídica llama, desde Hart, el caso fácil, esto es un caso en que se trata de comprobar si los hechos demostrados por el juez satisfacen la hipótesis de una norma y, subsecuentemente, no cabe sino atribuir una consecuencia normativa específica descrita en esa norma. Esto es no sólo posible sino deseable porque es la situación que mejor satisface el ideal de un juez que aplica derechos preexistentes a su propio entender acerca de la justicia del caso.

La segunda razón por la que no es trivial afirmar que el juez deba aplicar las normas pertinentes en el caso de los niños, es que la indefinición dogmática de la cláusula Inte- 
rés Superior del Niño hace pensar en ella como si fuera una cláusula general o concepto jurídico esencialmente controvertido (CEC) es decir, un concepto fácil de situar pero difícil de aislar conceptualmente porque sus posibilidades interpretativas son amplísimas por no decir infinitas como libertad, igualdad, orden público, etcétera.

Por lo anterior es conveniente advertir que, a menos que el juez pueda explicitar el argumento justificatorio de su decisión respecto del niño no hay ninguna garantía de que la decisión respeta su interés superior. En otras palabras, la vigencia normativa del interés superior en el contexto de la CIDN, depende de una correcta explicitación del argumento justificatorio de la decisión judicial y, en consecuencia, de la satisfacción de criterios de corrección argumental.

\section{Los argumentos}

No obstante el enorme despliegue teórico en torno el fenómeno de la argumentación podemos dibujar lo que un autor ha denominado la célula básica del argumento o lo que puede considerarse la estructura fundamental de cualquier argumento (Toulmin) del siguiente modo:

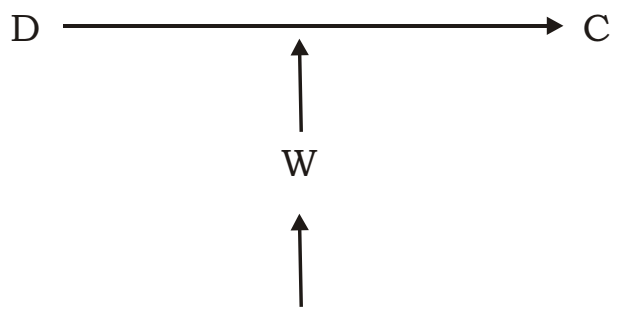

B

Desde este punto de vista la argumentación es una operación que se apoya sobre un enunciado asegurado (aceptado)el argumento- para llegar a un enunciado menos asegurado 
(menos aceptable) - la conclusión. Asi argumentar es dirigir a un interlocutor un argumento, es decir, una buena razón para hacerle admitir una conclusión e incitarlo a adoptar los comportamientos adecuados. ${ }^{22}$

El argumento tiene el status de una creencia (presentada como) compartida, de un dato fáctico (presentado como) incontestable. Evidentemente el destinatario de la argumentación puede rechazar ese dato, pero, entonces, tiene que justificar el rechazo: la carga de la prueba será responsabilidad suya.

Los enunciados de la conclusión. En argumentación la palabra conclusión tiene un sentido relativamente específico. La conclusión de un texto se define bastante mecánicamente como el final de ese texto. La conclusión mantenida por un texto puede muy bien aparecer en primer lugar, precediendo al argumento. La operación argumentativa permite así, transferir a objetos nuevos o a nuevas situaciones, saberes, creencia o comportamientos probados.

De esta suerte la estructura básica ya expuesta puede ejemplificarse, de la siguiente manera:

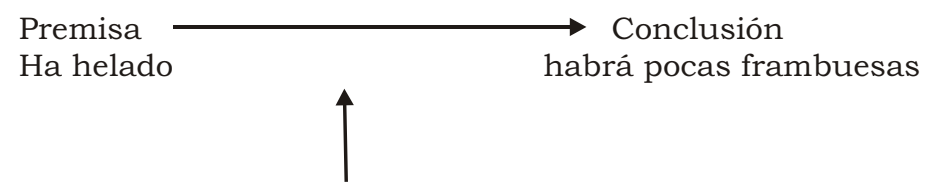

Ley de paso

El hielo destruye las frambuesas

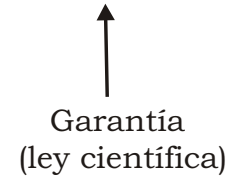

Siendo esta la estructura elemental de cualquier argumento en cualquier ámbito del saber racional este tipo de

22 Plantin, Christian, La Argumentación, 7a. ed., trad. de Amparo Tusón Valls, Barcelona, Planeta, 2010, pp. 33-44.

137 
estructura puede desempeñar un papel (al menos formal) en la toma de decisiones y ayuda a construir una respuesta a tres tipos de preguntas: ¿Qué debemos creer? O ¿Debemos creer esto?; ¿Qué debemos hacer? o ¿Debemos hacer eso?; ¿Qué tenemos que pensar de esto? ¿Es hermoso, está bien? Ni que decir que dentro de este esquema caben todos los tipos de inferencia conocidos. ${ }^{23}$

Puede afirmarse que éste es el esquema básico que satisface los requerimientos argumentativos de cualquier justificación de decisiones. La peculiaridad de las justificaciones prácticas y especialmente las jurídicas es que la garantía que respalda la ley de paso debe ser derecho vigente lo que de suyo constituye un criterio de justificación externa.

Una primera conclusión obvia que uno puede obtener de la sola observación del esquema expuesto es que una justificación que dijera, por ejemplo, "que atendido el interés superior del niño se resuelve en el sentido X, Y o Z", no es un argumento en ningún sentido técnico relevante, puesto que en ningún caso puede ser justificado sin referencia a algún universal explicativo o abarcativo de la situación particular que se está resolviendo. Se dirá que esto es trivial, pero no es inusual ver este tipo de afirmaciones en resoluciones judiciales sobre asuntos que incumben a los niños.

La segunda tesis que resulta naturalmente de la observación de este esquema argumental es que la ley de paso alude a algún criterio o regla que refiera un caso en términos generales (un universal). Es decir, más allá de la exigencia constitucional que los jueces tienen de usar reglas o principios para decidir, la existencia de un universal que conecte el enunciado asegurado (lo que se sabe con certeza acerca del caso, acerca del niño) con la conclusión, decisión final del juez (lo que no se sabe del caso), necesita una regla o criterio que se refiera al mismo en términos generales para poder ser justificada racionalmente. Nótese lo que se desprende de esto, que la tesis del interés superior integrada por derechos contenidos en reglas o principios es condición

23 Idem. 
necesaria (aunque no suficiente) de la justificabilidad de las decisiones estatales en materia de infancia.

\section{Tipos de norma y tipos de argumentos}

A partir de este punto y en más, la teoría de la argumentación jurídica ha desarrollado una larga exploración y se diría incluso un encendido debate acerca de la forma específica en que se argumenta dependiendo de si lo que se aplica es una regla, un principio u otro tipo de enunciados.

Creo que una parte importante de las dificultades argumentales vinculadas con la idea del Interés Superior del niño están asociadas a una incorrecta identificación del criterio normativo en términos analíticos. Tiende a pensarse que la redacción extremadamente general de la cláusula del Interés superior del niño respalda la idea de que se trata de un principio al modo entendido por Dworkin y que ello implica necesariamente un comportamiento argumental como el que ofrece Robert Alexy, ${ }^{24}$ i.e., el de una norma cuyo contendido debe ser ponderado y balanceado con otras consideraciones valorativas concurrentes. Sin embargo, por los motivos a que ya se ha hecho referencia, ello no es necesariamente así. Como la idea de interés superior del niño remite a la adjudicación de derechos nada excluye que la misma tenga lugar desde una regla de acción en la que ese derecho esté "contenido", eso es algo que ya el propio Alexy habia advertido en las primeras formulaciones de su teoria; los derechos pueden estar en reglas o principios. En este caso la regla de acción del tipo que establece que si se dan ciertos hechos operativos (OF) ha de seguirse la consecuencia normativa en relación con esos hechos (NC) del modo siguiente:

24 Véase supra n. 8. 
RICARDO GARRIDO ÁLVAREZ

«Si $O F$, entonces $N C$

$O F$

luego $N C$ "

Esto abre, para la argumentación en materia de derechos del niño, el certero y muy deseable campo de la deducción. Como puso de manifiesto con brillantez Niel MacCormick "Lo que hacen las normas juridicas es seleccionar algunos hechos - acciones o sucesos- posibles del mundo, y estipular que ciertas consecuencias normativas han de ligarse a ellos en Derecho. Los hechos seleccionados en una regla pueden verse pues como "hechos operativos", porque cuando suceden operan en el Derecho para justificar que en el caso dado se derive la consecuencia normativa dada": Siempre que OF, entonces $N G$ ". ${ }^{25}$ Hay abundante evidencia de que esto ocurre (con más frecuencia de la que se piensa) en materia de derechos del niño y como se ha venido explicando perecería que esta es la forma deseable de adjudicación atendidas las pretensiones de objetividad y racionalidad que pesan sobre las decisiones judiciales en materia de infancia.

A decir verdad los problemas que según la teoría estándar de la argumentación, aparecen en los llamados casos difíciles y que dificultan la argumentación silogística en el modo en que ha sido someramente presentada parecen ser problemas que es necesario despejar para que las premisas del argumento queden por decirlo de alguna manera, "en estado" de ser aplicadas silogísticamente. Lo anterior no ex-

25 Véase supra n. 4. 
cluye que estos distintos problemas fuercen argumentaciones adicionales o complementarias "al interior" del argumento justificatorio general.

Manuel Atienza ha sugerido que la identificación del tipo de norma que se aplica es clave para la explicitación correcta del razonamiento justificatorio. ${ }^{26}$

Así, si la norma a aplicar es una norma de acción, es decir, como la que se citaba, forzaria un argumento subsuntivo o clasificatorio, esto es, si se establece que se dan determinadas condiciones de aplicación (un caso genérico) entonces alguien debe, puede o está obligado a realizar una determinada acción y por lo tanto la explicitación del argumento sería, y como se citaba más arriba, la de un modus ponens que expresaría la inferencia deductiva en cuestión:

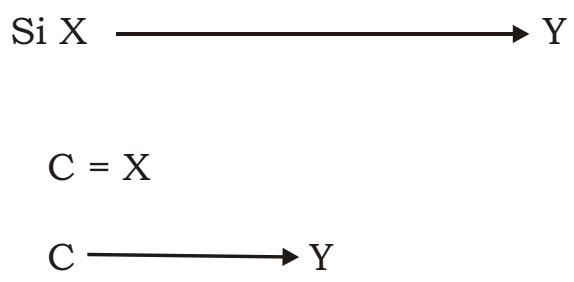

Es conveniente recordar acá que como este razonamiento se da en el contexto de un discurso de aplicación de reglas no expresa ninguna trivialidad o cuestión auto evidente puesto que el juez debe mostrar que el caso está, realmente, alcanzado por la norma que estimó o seleccionó como aplicable.

Por otro lado, sigue Atienza, podríamos encontrarnos ante una norma de fines, que tendría la forma de lo que él

26 Atienza, Manuel, Las razones del derecho. Teorias de la argumentación jurídica, 2a. reimp., México, UNAM, Instituto de Investigaciones Jurídicas, 2005, p. 251. 
llama adecuación, también denominado, argumento finalista o razonamiento práctico, este tendría la siguiente forma:

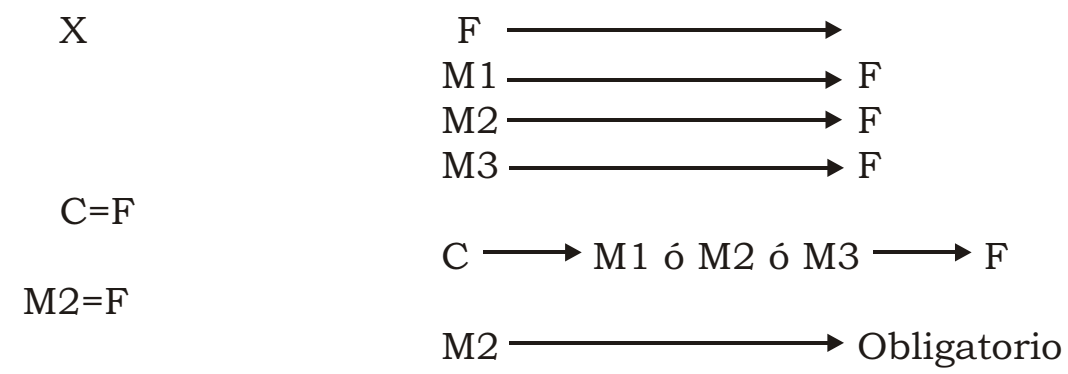

Dos importantes comentarios deben ser efectuados en este punto: En primer lugar, la definición estipulativa de este trabajo de que el Interés Superior del Niño implica la más amplia satisfacción de los derechos del mismo, sugiere que muchas reglas o criterios normativos que están mediados por la idea de interés superior se "convierten" en norma de fin. El caso típico es de las disputas parentales sobre la custodia o cuidado personal de los hijos podría formularse a la luz de la CIDN, del siguiente modo: Cuando los padres viven separados debe dejarse la custodia de los hijos a quien asegure la maximización en el disfrute y protección de los derechos del niño. Es decir, la cláusula del interés superior del niño es ella misma una norma de fines.

En segundo lugar debe observarse que la atención a las consecuencias que la decisión tiene para el niño no opera en ese nivel como un criterio de justificación externa, esto es, como un criterio que permita discernir o preferir entre interpretaciones plausibles para la norma usada (que sería el caso de considerarse esto un principio y no una regla) sino que los alcances de la regla y las hipótesis que la hacen aplicable están perfectamente delimitados y el criterio de maximización de los derechos como finalidad de la reglas proyecta una necesidad u obligación argumentativa especí-

142 
fica en términos de explicitar las razones que hacen a un curso de acción preferible al otro u otros disponibles para el caso.

\section{CONCLUSIÓN}

Sugerida la idea de que la cláusula del interés superior del niño introduce un criterio finalista de maximización de los derechos se puede concluir que esta forma argumentativa debería ser de un amplísimo y extendido uso en materia de derechos del niño y que su ausencia en la práctica se debe a una incorrecta identificación del tipo de norma aplicable más que a las dificultades interpretativas que suelen reprocharse a la idea del interés superior del niño.

Por último, atendido que el interés superior consiste en los derechos que deban adjudicarse al niño objeto de decisión por parte del órgano estatal, está claro que en muchos casos habrá colisiones y dificultades interpretativas propias de la redacción necesariamente amplia y vaga que tienen los derechos humanos o fundamentales. Sin embargo insistiría, que ello no necesariamente fuerza un argumento de tipo ponderativo por varias razones. En primer lugar, porque habrá muchos casos en que la dogmática y los criterios precedenciales ayudarán a despejar eventuales problemas interpretativos, de calificación y relevancia del criterio normativo aplicable a la solución de un caso, en segundo lugar porque del hecho de que lo que deba adjudicarse sea un derecho constitucional no se sigue que este sea siempre ponderado o equilibrado con intereses concurrentes, a veces es solo dato que se trata de un derecho fundamental y este dato servirá para descartar interpretaciones implausibles o inaceptables desde el contenido básico o elemental del derecho.

Finalmente habrá casos en que necesariamente debe recurrirse a criterios de justificación externa (precedente atención a las consecuencias universalización, etc.) que nos ayuden a despejar colisiones o dificultades interpretativas 
no resueltas dogmáticamente pero debe quedar claro que estas dificultades y colisiones no aparecieron con la cláusula del Interés Superior del Niño sino que corresponden a las dificultades de aplicación e interpretación de cualquier derecho fundamental o humano.

Por el contrario, la cláusula del interés superior contiene el germen de un mecanismo de solución para esa dificultad interpretativa o aplicativa la idea de que el énfasis debe ser puesto en la satisfacción de los derechos del niño y no en otros intereses, derechos o consideraciones concurrentes, tal vez este sea el principal defecto de la solución de salomón, adoptada, como está, sin prestar atención alguna a los intereses del niño que era afectado por la decisión y como diría Amartya $\operatorname{Sen}^{27}$ construido bajo la ilusión posicional de una situación, la de los niños, que nos hemos negado a ver por siglos. ${ }^{28}$

27 Sen, Amartya, La idea de justicia, Buenos Aires, Taurus, 2011, p. 192. La idea de la ilusión posicional es explicada por Sen en términos de la Ilusión objetiva (Marx) o de la "Imparcialidad abierta" (A. Smith). Alude a la idea de que una opinión o juicio que es independiente de la posición puede estar contaminada por discriminaciones y prejuicios históricos y sociales que no son independientes de ella. El usa como ejemplo, la situación de las mujeres y la ciencia, el dato "objetivo" de que hay pocas mujeres científicas y que puede llevarnos a inferir que las mujeres no tienen habilidades para la ciencia, está claramente determinado por el dato cultural e histórico de que ellas han tenido un menor acceso a la educación formal, lo que puede cotejarse con el dato de países en que el acceso a la educación es más igualitario. Él explica que incluso "cuando una posición es adecuada para una evaluación epistemológica, ética o política, las observaciones reales que dependen de la posición pueden tenerse en cuenta para explicar la dificultad de enlazar una comprensión posicionalmente libre de prejuicios". Para nuestro caso implicaria que las decisiones tomadas sobre la base de reglas e información pretendidamente objetiva acerca de los niños, ha ocultado el posicionamiento adulto desde el cual esas decisiones han sido realmente adoptadas.

28 Es posible leer esta forma específica de defender la cláusula del interés superior del niño como una versión argumental del instituto de la "norma más favorable" a los derechos de las personas o pro homine, el cual contribuye a prevenir o minimizar las posibilidades de conflictos en la aplicación de los tratados internacionales y la legislación interna de los 
EL INTERÉS SUPERIOR DEL NIÑO Y EL RAZONAMIENTO JURÍDICO

\section{BIBLIOGRAFÍA}

ALEXY, Robert, Teoría de la argumentación jurídica, 2a. ed., trad. Manuel Atienza e Isabel Espejo, Madrid, España, Centro de Estudios Políticos y Constitucionales, 2008.

, "La formula del peso", en CARBOnELL, Miguel (coord.), El Principio de Proporcionalidad en la Interpretación Jurídica, Centro de Estudios de Constitucionales de la Universidad de Talca-UNAM, Instituto de Investigaciones Jurídicas, 2010.

_ - Teoría de los derechos fundamentales, trad. Ernesto Garzón Valdés, Madrid, Centro de Estudios Políticos y Constitucionales, 2002.

AtiEnZA, Manuel, Las razones del derecho. Teorías de la argumentación jurídica, 2a. reimp., México, UNAM, Instituto de Investigaciones Jurídicas, 2005.

ATRIA, Lemaitre Fernando, "Seguridad jurídica y derechos fundamentales: Sobre predecibilidad y autogobierno", en BORDALÍ, Andrés (comp.), Justicia constitucional y derechos fundamentales, 2a. ed., Santiago, Chile, Lexis Nexis, 2007.

BIX, Brian, Diccionario de Teoría Juridica, trad. Enrique Rodríguez Trujano y Pedro A. Villarreal Lizárraga, Méxi-

Estados. El principio favor homine determina la necesidad de buscar siempre la norma más beneficiosa y favorable a los derechos de la personas, ya sea que se encuentren en la fuente internacional o en la fuente interna. Dicho principio se infiere del articulado 29 de la Convención cuando admite que se invoquen los derechos consagrados en ella y en el pleno de derechos que pueden estar previstos en otras fuentes. En algún sentido lo que la idea de interés superior del niño define es la pretensión de prosecución de la posición más favorable para su destinatario (en este caso específico: el niño) ya no en el marco de las fuentes del derecho estrictamente sino en la maximización de las normas en juego (nota del autor). 
RICARDO GARRIDO ÁLVAREZ

co, UNAM, Instituto de Investigaciones Jurídicas, 2009.

Cillero BRUÑOL, Miguel, "El interés superior del niño en el marco de la convención internacional sobre los derechos del niño", Justicia y derechos del niño, núm. 9, Santiago de Chile, 2007.

CORTE INTERAMERICANA DE DEREChOS Humanos, Sentencia del 31 de enero de 2001, Serie C, No. 71, párrafo 89.

DOXA. CUADERNOS DE FILOSOFÍA DEL DERECHO, "Entrevista a Robert Alexy", en Doxa. Cuadernos de Filosofía del Derecho, núm. 24, trad. Manuel Atienza, España, Universidad de Alicante, Departamento de filosofia del derecho, s/f.

DWORKIN, Ronald, El imperio de la justicia, Barcelona, España, Gedisa, 1992.

- L L L democracia posible. Principios para un nuevo debate politico, Barcelona, España, Paidós, Col. Estado y Sociedad, 2008.

- Los derechos en serio, trad. de Martha Guastavino, Barcelona, Ariel, 1989.

FERRAJOLI, Luigi, Democracia y garantismo, edición de Miguel Carbonell, 2a. ed., Madrid, España, Editorial Trotta, 2010.

GOLDSTEIN, Joseph et al., ¿En el interés superior de quién es? Beyond the best interests of the Child. Derecho, infancia y familia, compilado por Mary Beloff, Barcelona, Biblioteca Yale de estudios Jurídicos, 2000.

Goldstein, Joseph et al., Beyond the Best Interests of the Child, 1973-1979.

GÜNTHER, Klaus, "Critical Remarks on Robert Alexy "Special-case Thesis"”, Ratio Juris, 6.

HABERMAS, Jürgen, Teoría de la acción comunicativa: complementos y estudios previos, 4a. ed., trad. de Manuel Jiménez Redondo, Madrid, Cátedra, 2001. 
Holmes Stephen y Sunstein, Cass R., El costo de los derechos. ¿Por qué la libertad depende de los impuestos?, Buenos Aires, Siglo XXI, 2011.

$-\mathrm{y} \longrightarrow$, El costo de los derechos, trad. de Stella Mastrangelo, Buenos Aires, Siglo XXI, 2011.

MACCORMICK, Neil, "La argumentación silogística: una defensa matizada", Doxa. Cuadernos de filosofía del derecho, 30, España, 2009.

_- "Sobre el concepto de razonabilidad", trad. de Fernando Atria, Revista de Ciencias Sociales, Valparaíso, Universidad de Valparaíso.

MEDINA, Cecilia, "El derecho internacional de los derechos humanos", Sistema Juridico y Derechos Humanos, Cuadernos de Análisis Juridico Ediciones especiales $n \mid \&$, Universidad Diego Portales, Santiago de Chile, 1996.

Nino, Carlos Santiago, Ética y derechos humanos. Un ensayo de fundamentación, Buenos Aires, Astrea de Alfredo y Ricardo de Palma, 1989.

Plantin, Christian, La argumentación, 7a. ed., trad. de Amparo Tusón Valls, Barcelona, Editorial Planeta, 2010.

RAZ, Joseph, La ética en el ámbito público, trad. de María Luz Melón, Barcelona, Gedisa, 2001.

—- Razón práctica y normas, Madrid, Centro de Estudios Constitucionales, 1991.

SEn, Amartya, La idea de justicia, Buenos Aires, Taurus, 2011.

WROBLEWSKI, Jerzy, Constitución y teoría general de la interpretación juridica, trad. de Arantxa Azurza, Madrid, Civitas, 1985. 
DR (C) 2013, Universidad Nacional Autónoma de México,

Instituto de Investigaciones Jurídicas 